
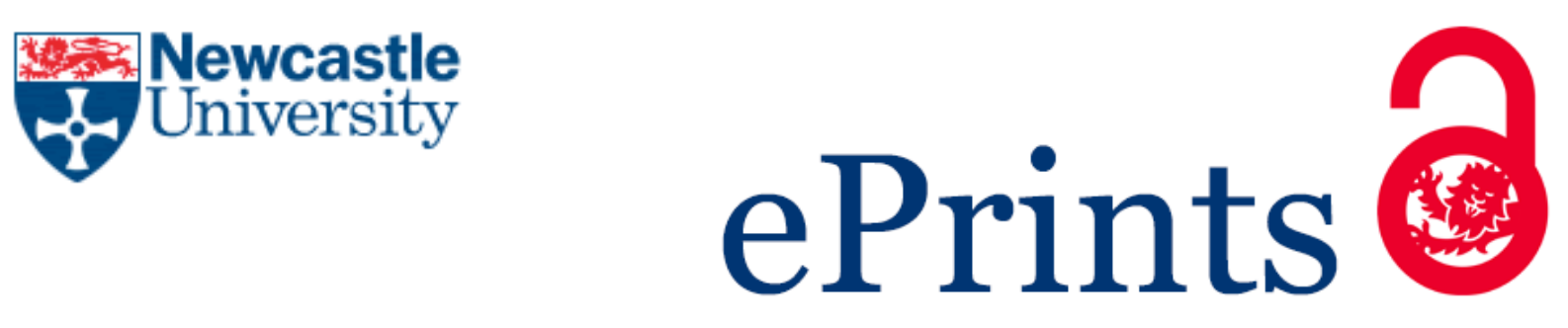

Woolner P, Clark J, Laing K, Thomas U, Tiplady L. A school tries to change:

How leaders and teachers understand changes to space and practices in a UK secondary school. Improving Schools 2014, 17(2), 148-162.

Copyright:

(C) The authors, 2014.

DOI link to article:

http://dx.doi.org/10.1177/1365480214537931

Date deposited:

$31 / 07 / 2015$

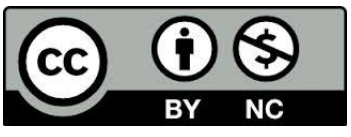

This work is licensed under a Creative Commons Attribution-NonCommercial 3.0 Unported License 


\title{
A school tries to change: how leaders and teachers understand changes to space and practices in a UK secondary school
}

\author{
Pamela Woolner, Jill Clark, Karen Laing, Ulrike Thomas and Lucy Tiplady \\ Research Centre for Learning and Teaching, Newcastle University, UK
}

Corresponding author: Pamela Woolner: pamela.woolner@ncl.ac.uk

\begin{abstract}
This paper considers a school community initiating change in pedagogical practices to complement new-build premises in the context of demands for school improvement, but constraints on autonomy. We investigate how school leaders planned the change towards enquiry-based learning in flexible spaces, and how teaching staff prepared for the coming change. We worked with teachers to explore current experiences of teaching and learning in self-contained classrooms where teachers mainly teach alone, and anticipations for the new building, where there will be large, shared spaces, facilitating movement and different groupings of students, encouraging student autonomy and teacher teamwork. Preparation for change was centred on an 'experimental week' of enquiry learning that took place in an existing large space (a school hall). Here we explore the experiences of the teachers involved, particularly their ideas about the potential for changing practices, considering these in light of the plans of the school leaders and of wider understandings of school change. We met the teachers before and after the experimental week, observed the week and conducted interviews mediated by photographs of the week. The tensions and stresses of attempting to make extensive changes to teaching practices were evident, together with suggestions that the school leaders were failing to appreciate the complexity of the change they were planning or to communicate the ideas about it that they had developed. The probable consequences for the school, given the uneven distribution of autonomy in UK schools, are briefly considered.
\end{abstract}


Key words: learning environment; enquiry-based learning; open plan; flexible; team teaching

Acknowledgement: This article is adapted from a paper presented at ECER 2013, Istanbul 10-13 Sept 2013, and has benefited from discussion then and since, for which we are grateful.

Funding: This work was supported by funding from Creative Partnerships

\section{Introduction}

Enacting change in educational practices is notoriously difficult, with research clarifying in particular the gaps that can develop between policy and practice, and suggesting the need for school communities to be active participants rather than the recipients of top-down 'reform' (Thomson, 2007; Hargreaves, 2002; Ouston el at., 1991). Although some recent government initiatives in the US and UK appear cognisant of this necessity (e.g. Scottish curriculum reform, see Priestley et al., 2011), it has been argued that there is inequity in the enabling of school-led development (Thomson et al., 2009), offering 'freedom to change to the affluent and fear of failure to the rest' (Hargreaves, 2002: 206).

This article describes the attempt by a school that found itself in challenging circumstances to wrest back this autonomy and innovate through changing the setting, curriculum and practices of learning.

\section{School Context}

The school is a non-selective secondary school of approximately 1000 students, aged 11-16 years, formed by the recent merger of two schools that had formerly used separate buildings on a shared site, with a new school building under construction at the time of our research. This school is located in an area which has lost much traditional employment, producing concerns that students lose motivation and develop limited aspirations as a result of poor employment prospects. Due to this post-industrial situation the local population is steady or decreasing and the school competes for its intake with a number of other secondary schools. School leaders therefore felt the need to 
establish the school as distinctive. In considering how to do this while meeting the needs of the students, the head teacher and other senior staff were preoccupied by decreasing achievement within the lower school years that will translate into lower attainment at GCSE in a few years if no changes are made to pedagogical practices. As well as failing these students, such reductions in GCSE results could prove disastrous for the school given the current UK climate of league tables of exam results and the encouragement of parents to choose schools on this basis.

The response of the senior management team was to review the school curriculum, through which they intend to spearhead a transition to learning which emphasises skills and competencies over content knowledge, and the development of 'enquiry' based learning. This approach intends students to collaborate with teachers and their peers to develop their own learning, and it was anticipated that the new school building would actively support, rather than hinder, this style of learning, giving students more autonomy through the provision of shared space. The intention was that interdisciplinary, enquiry-based learning facilitated by flexible use of bigger spaces and teams of teachers would replace traditional teaching of separate school subjects by one teacher in an enclosed classroom with classes of 25 to 30 students. This change in pedagogy was to be supported by organisational change where existing school 'departments' were to be combined into five new 'faculties', bringing together related disciplines such as maths and science, pulling together previously more disparate subject knowledge and encouraging more interdisciplinary working among staff.

In essence, the school leaders were hoping to change the culture of the school through making alterations to tangible aspects such as department organisation, curriculum and, importantly, the physical space.

\section{Practices, space and the culture of schools}

Cultural understandings are intimately related to school practices and exist at a number of levels from societal expectations of education (Lowe, 2007), professional and pedagogical 
understandings among staff (Cuban, 1993) and, vitally, the culture of the particular school. The same intentions or policies are enacted through different practices in different schools (e.g. Priestley et al., 2011). Similarly, a relationship has been found between style of physical environment and teaching practice (Horne Martin, 1999, 2002; Sigurðardóttir \& Hjartson, 2011), but identical spaces can be used in different ways in different schools (Bennett et al., 1980: 217) and it is clear that the ethos of the school affects the way space is engaged with, organised and used (Uline et al., 2009). Conversely, 'the physical environment is a visible sign of the school's culture: tangible evidence of its values, norms and behaviours' (Briggs, 2001: 176). In understanding alterations in practices, including why change fails to occur, such ideas about culture are useful.

To consider the detail of how educational practices and school setting fit together, Gislason has proposed a model with four components: staff culture, student culture, 'organisation', which is comprised of aspects such as timetabling and curriculum, and 'ecology', comprised of physical and technological resources (Gislason, 2010: 129). These ideas resonate with Moos' earlier model that sees 'classroom climate' resulting from interactions of teacher characteristics, student characteristics, 'organisational factors' and 'physical and architectural features' (Moos, 1979: 161). Although we might question the separation of teacher and student factors, since the school culture must depend on both, with learning experiences emerging from their interaction, these models make sense in relation to our previous work in this area (Woolner et al., 2007; Woolner et al., 2012b).

These models can potentially explain some historic examples of occasions when alterations were made to physical learning space but change in educational practices failed to happen: it can be proposed that developing new practices will tend to require changes that may include, but should not be limited to, changing the physical space (Bennett et al., 1980; Cooper, 1981). Such models may also be useful in thinking about altering pedagogical practices to include more team teaching, for example, a change often proposed in connection with more flexible use of space, which has been shown to be difficult to enact (York-Barr et al., 2007; Graue et al., 2007): in this case, the 
change made is organisational, but what is desired is change in teaching and learning and, arguably, a change in culture. It might be questioned whether the school culture can be altered directly or whether it is an emergent feature that will tend to change as a result of successful change to other aspects. This is suggested by Moos' model, although not by Gislason's. Additionally, neither of these models prescribes an order for making changes within their systems and empirical work may be beneficial in this respect.

\section{Collaborative research and the Experimental Week}

In the school we worked with, change in teaching and learning practices was actively pursued by the school leaders, primarily through organisational and physical change, but with awareness that for change to be successful staff and student culture, their expectations, intentions and understandings of teaching and learning in this school, would also need to alter. One way to encourage and support such change would have been the participation of staff and students in the design process, but this had been limited by the school's circumstances as a new school, with the new staff not formally appointed and the students still members of the two former schools when the build was at the design stage. Instead the school leaders decided to use the time while the new building was under construction to make organisational changes to support the intended move towards the new teaching and learning practices. This was also the time used to attempt to shift staff and student cultures, particularly relating to learning and teaching, which was the point when we became involved.

Senior leaders had planned for the organisational change to the new faculties, and so more interdisciplinary working, to proceed a full year before the move into the new building. During the year before this reorganisation into faculties, it was intended that a transition in practices and pedagogical understanding was to begin. More enquiry based learning would be planned and attempted, specifically in response to an 'experimental week', which took place in the middle of the school year. 
This experimental week of enquiry based learning was conducted by teams of teachers with a large group of students (approximately 80 Year 8 pupils, aged 12-13 years) in an existing open space. During the week, teaching staff worked across existing departments within the new faculties, with each faculty having responsibility for arranging enquiry based learning relating to their disciplines for one day of the week. The curriculum was organised around a main theme of a local landmark bridge. The students were chosen by senior teachers in collaboration with form tutors and subject teachers to represent students' full ability range, but the school leaders decided to exclude students whose behaviour might be challenging or difficult. The teachers' involvement was broadly voluntary and discussion with them revealed a range of views. Although some got involved in the experimental week because they were particularly enthusiastic about the new approach, others had considerable misgivings.

We were engaged to facilitate the teachers' reflections on learning and teaching as they prepared for the week and as they considered the experience afterwards. Our research interest centred on the experience of both the teachers and students during the week, and how this related to their understandings of learning and teaching before and afterwards. We have discussed the student perspective elsewhere (Woolner et al., 2012a) and here we will be concentrate on the staff.

The discussions we facilitated within the faculty groups and our conversations with the teachers were mediated by various items and activities, many visual in nature. The intention was to initiate and facilitate discussion with and between a range of staff representing different disciplines and with varying levels of seniority. Previous work has demonstrated the advantages of visually mediated encounters in encouraging the participation of diverse groups of people, facilitating discussion about unarticulated or implicit experiences and ideas, and building understandings within a group and as part of an iterative process over several sessions (Bragg and Buckingham, 2008; Clark, 2010; Woolner, 2010; Woolner et al., 2010;). We will be referring to the staff sessions before and after the week, which formed the core of the teachers' reflection and collaboration processes. These meetings were intended to involve all the staff who facilitated the enquiry learning during the week, equating to between 4 and 6 teachers from each of the five faculties. 
One member of the research team was present at meetings before the week with school leaders, and, during the experimental week, two members of the team observed three of the five days with the intention of noting how teaching and learning activities were organised in the space available and how the days were experienced by students and teachers. In addition, we conducted one to one interviews two months after the week with some of the participating teachers and also several of the school leaders, facilitated by photographs of the week taken by a professional photographer who was engaged as part of the project.

At the initial meeting with the teachers, the first activity involved them working in their faculty groups to 'diamond rank' (see Clark, 2012; Woolner et al., 2010) nine images of teaching and/or learning according to the extent to which the photographs showed 'good learning happening' as opposed to 'poor learning or less learning'. Within faculty groups, we then focused on developing discussions about the 'hopes' and 'concerns' of staff regarding the experimental week. During the session with the teachers after the experimental week, we facilitated reflection on their experiences of the week through a range of methods. These included presenting quotes from students for discussion, revisiting the diamond rankings produced during the first session, viewing a continuous slideshow of the photographs taken during the week and asking for their advice to the rest of the school regarding changing pedagogical practices. Approximately a month after this, we returned to the school and conducted the one-to-one interviews mediated by photographs with teacher participants and also members of the leadership team (interview data presented below is taken from three interviews with leaders and four with teachers).

In the following sections, we will present and discuss the understandings and experiences of the school leaders, who initiated the proposed changes, and of a sample of the teaching staff who were tasked with enacting them and were involved in the experimental week. This has been achieved through examining the data collected during the various encounters with the leaders and with teachers from two of the five new faculties. This focus enables us to consider a range of viewpoints without an overload of detail that might obscure understanding, although clearly this narrow analysis is informed by our experiences with the wider pool of staff and, indeed, with the 
students also. In choosing two faculties to examine, we prioritised contrast and have selected a faculty ('Creation', comprised of ICT and Design and Technology departments, together with business studies) where staff already did some interdisciplinary work and were broadly enthusiastic about developing an enquiry based approach together with a faculty ('Explanation', comprised of the existing mathematics and science departments) which brings together a pair of quite separate departments and includes teachers with doubts and concerns about the proposed changes.

\section{Before the Experimental Week}

\section{Teaching and Learning Experience}

Senior leaders perceived a lack of aspiration and a certain cynicism among the students, which they hoped could be addressed through changes to teaching and learning practices. The proposed enquiry based learning was intended to engage students in learning through the types of interdisciplinary problems that people experience in the real world. Senior staff hoped that an enquiry learning approach in a shared space might enable pupils to work more independently, respect each other and give them more self-belief as well as a willingness to take risks and try new things.

Nevertheless, senior leaders were aware that they needed to get staff on board in order for this approach to work. There was a perception that staff would fall into two camps: those that were keen on a new way of working, and those who were unsure. There was a perception of a core group of teachers who were keen, but uncertainty about how many, and whether they would be enough to inspire others. The judgement of the school leaders was that in order to get teachers on board, there was a need to engage in dialogue, and practice the approaches, following a period of teacher development that took into account teachers mental models of teaching and learning yet sought to place enquiry based learning at the centre of their practice.

\footnotetext{
${ }^{1}$ The names given to the two faculties are pseudonyms
} 
Our initial discussions with the teachers suggested that they were open to pedagogical change since they saw the potential of a curriculum that would be more engaging, could foster group work and collaboration, and encourage greater independence amongst students. It was felt that at present students struggled to lead their own learning and take risks. It was hoped that a more relevant, enquiry based learning approach would ultimately raise students' aspirations and achievement. Whilst there was a general agreement amongst teachers that this new approach had the potential to be transformative and was therefore desirable, there were also a variety of concerns raised.

Some teachers, particularly those in core curriculum areas, had concerns relating to content knowledge, differentiation and adequately preparing students for exams. For these teachers collaborative, cross curricular and student led learning was wholly different to current practices and led to varying degrees of anxiety; in one case a teacher informed the researchers that he had resigned on the basis that he did not want to teach in this way. However, this was not universally felt and for those teachers in subjects that had a history of adopting cross curricular projects, it was simply expressed that 'we do this already'. All the teachers involved in the experimental week were aware of the need to capture students' enthusiasm for this new vision and approach and so were keen that the week should be a success in terms of student enjoyment and engagement.

\section{Organisation}

Senior leaders were aware of other innovative approaches which had been tried in schools near them, talking, for example, of a 'chairless school' where pupils worked in bigger learning spaces in larger groups.This, nevertheless, was tempered by knowledge of the the tensions inherent in the rigidity of the curriculum and the time needed to cover content, perceived to take longer through an enquiry learning approach. Their intention was that the reorganisation into faculties, in which subject departments were grouped together, would initiate inter-disciplinary communication and working. 
Teachers recognised that this new organisational structure would alter practices, and discussed how cross curricular projects could be the basis for teaching and learning; it was felt that this would enable students to develop an awareness of learning across subject areas. The teachers expressed the need for strong and supportive leadership and management during the transition years; specific requests included time, resources and a consistent whole school behaviour management policy. Time related particularly to collaborative teacher planning, which would be crucial in making the cross curricular enquiry based projects a success.

\section{Physical space}

Several practical problems with the new school environment were anticipated by the school leaders linked to the changed way of working. Senior staff felt that the noise levels might be a problem in a large shared space, and had considered the possibility of giving teachers microphones. Staff would not have their own classroom, or territory that they could make their own, and school leaders wondered about possible impacts on professional identity. Shared planning would be needed, and a common language of learning needed to be developed. Shared spaces would entail collective responsibility for keeping them in order.

The teachers also expressed concerns about moving out of traditional classrooms: one commented that at present it can be a challenge to get students to sit in their seats at the beginning of the lesson and asked "without walls how is it going to work?" This was particularly in reference to gathering the whole class together, for example during starters and plenaries. However, it was also felt that the open plan spaces would provide students with more physical freedom under the supervision of staff, which it was hoped would improve student behaviour.

Considering the setting for learning, during the Day 1 discussions, 'Explanation' drew attention to a classroom layout that provided 'opportunity for collaboration' and commented on the benefits of a 'different environment' in referring to images of groups of students outside. The diamond produced by 'Creation' included a criticism of a classroom with 'too much clutter'. 


\section{After the Experimental Week}

\section{Teaching and Learning Experience}

In both the faculties whose Day 2 discussions were analysed there was a strong element of positivity running through their comments, both in terms of facilitating enquiry learning and the teachers' impressions of the student experience. Mostly the teachers (and also the senior leaders) felt that students had enjoyed the week, had engaged very well with learning through methods such as group work and guided research, and had in general learnt something.

The groups of pupils all looked engaged in learning, they all looked like they were enjoying themselves and were not self-conscious. (L., ICT teacher)

The kids seemed to get a lot out of it..... (J., maths teacher)

Once they go into the building part, they were very engaged and some of them asked if they could stay over dinner-time. (A., science teacher)

Comments relating to students mentioned movement quite frequently, often linked to ideas of independence, but there were also some comments voicing concerns about certain students who might not benefit from the style of learning, in particular SEN students. There was a brief discussion about some students and some learning requiring the opportunity for private study. This worry about students being fundamentally unsuited to this way of working was of more concern among the 'Explanation' teachers, whereas the 'Creation' teachers discussed the challenges of engaging certain 'characters' and leaving them no time to misbehave.

Insert Fig 1 here 
Some of the maths teachers within the 'Explanation' faculty also felt that their subject was unsuited to this way of working: 'maths is different' was a comment made. Relating enquiry-based learning to the curriculum was also noted as a concern by one maths teacher who told us:

.... of lessons that week, for me personally I missed five Year 8 classes and the content that was in that day didn't even touch what would have been a normal week. So that would be a concern for me. At the end of the day they've still got to get through everything that's in the curriculum. (J., maths teacher)

This teacher went on to say:

I asked them [Year 8s] if they felt that had done as much work in the week as they would have normally and they said 'no way!'. (J., maths teacher)

This view was supported by a science teacher:

There may be times when content can't be taught like this [EBL], it's a case of these are the facts we've got to learn. At the end of the day in Year 11 they've got an exam they have to be able to complete and feel confident that they will do well. (A., science teacher).

The senior leaders acknowledged these concerns, but felt that there was 'a place for everyone' with this style of learning. They referred to the previous experiences of these students in local primary schools, where much of the work is project based and cross-curricular, indicating that this is a style of working that students are already familiar with. Nonetheless, they realised that some children work better alone, or with a book, or are not as keen on certain subjects. This was particularly an issue when subjects were to be, in effect, taught for a whole day rather than short blocks of time. On balance, senior leaders felt that the structure of the new way of working allowed for flexibility, and enabled pupils to work in the ways which suited them. Although the senior leadership felt that there was a risk of people perceiving that the children had not learnt as much 
as they would have done in traditional lessons, they valued the 'deep learning' that they felt was going on:

There is undoubtedly a time when there is content that has to be covered, but I think that often, with core subjects that are very concerned about their content coverage, they're [pupils] taught it, but I'm not sure how much it would have been learnt and absorbed, whereas if you take the time to learn how to learn and the time to learn how to think, then that's deep learning that's then understood when you need it... that then stays with you better and can be applied better in different circumstances as well. (School leader)

The senior leaders also commented that the traditional roles of teacher and pupil had been challenged during the week. They felt that it was a benefit that teachers and students were seen in genuine collaboration, and that students were enabled to 'be the expert' in their own learning, rather than the teacher, who became a co-investigator or facilitator of learning.

In relation to both their own and the students' experiences, the teachers commented on the week being tiring and many of the comments referred to how busy or hectic their day of teaching had been:

It worked quite well, but I found it quite tiring, and I found as well that at break, instead of us getting a break as well, we found ourselves clearing and preparing for the next one. (J., maths teacher)

There was a general feeling that enquiry learning was very much a 'novelty' and that enthusiasm and interest would wain if it was done all the time:

The day has helped a little bit but I think the novelty of what was happening kept them interested, l'd like to see what would happen after a few weeks of doing that, but on that day they did really, really well. (A., science teacher) 
On a week to week basis I don't think we could keep that momentum going. But elements within it we could. (L., ICT teacher)

In many cases these comments about time and effort linked to a recurring concern: that of planning, which will be discussed in more detail below.

\section{Organisation}

Many of the teachers' comments during the Day 2 session related to the organisational challenges of facilitating this approach to learning. These ranged from immediate practical aspects, such as preparing enough material to keep students occupied, through discussions of arrangements for facilitating group work, to some discussions of issues arising from working across traditional subject boundaries. The experimental week had enabled the teachers to develop their appreciation of these aspects, including noting the ability of the students to adapt to group working situations as the week progressed, but this left them all similarly certain of the time required to plan such learning initially. There was evidence of a slightly more positive reaction to this conviction in 'Creation' where staff reported that they had used the faculty budget to go away for a planning weekend and had time arranged the following week to plan as a faculty for the following year's Year 7 students. Within 'Explanation', the comments centred on the time required to plan effectively and suggested a note of panic about how this would be possible: 'Three hours planning were not enough for one day... and we need to plan a whole year'.

In both faculties, the challenges of interdisciplinary working were mentioned. However, while the 'Explanation' teachers felt that they had struggled on the day to link maths and science, making merely 'tenuous links', the 'Creation' teachers' concerns were with how the teaching of particular skills could be harmonised across the whole school. This demonstration of more doubt about working between faculties than within their own faculty is presumably related to their existing practices, which they considered to be quite inter-disciplinary, and which tended to involve collaboration with other staff such as technicians. 
It was notable that an underlying feature of all the conversation about organisation was planning. Again and again, the teachers' discussions returned to the issue of finding time to plan:

The key aspect was time, to sit down as a group and think how are we going to work this what key concepts of the curriculum are we trying to hit? That's going to be the biggest challenge for setting it up if this is something that's going to happen all the time - it's finding the time for planning. (A., science teacher)

The two problems identified were that more time would be needed to plan for the new approach initially because it was new, but also that for genuine collaborative planning to occur there had to be opportunities for colleagues to get together and plan.

Insert Fig 2 here

When we asked the teachers to summarise their learning from the experimental week (see figure 2), 'planning' featured frequently in each section of the table and was offered as the essential action by both faculties:

Joint planning time

Progress centre needs to be involved in planning

SLT need to make time available

The response from 'Creation' was particularly striking: the learning featured detailed planning, pacing and lots of activities, narrowing to planning and a 'wide range of activities' as needing to be passed on to the wider school, but then reduced to just one action: that of senior leaders making time available for joint, collaborative planning. 


\section{Physical space}

Little of the teachers' discussions on Day 2 focused on the use of space, even though the experimental week had been explicitly about working in a different space and the teachers were all very aware of the layout of the new building being built. Even when the new school premises were mentioned, the tendency of the teachers was to focus on the challenges of interdisciplinary enquiry learning and collaborative teaching rather than on the space itself:

When the new building comes in, this is going to be how a week will be - they will have half a day with Explanation, half a day with others. So this is what they will do. This is completely different from anything l've done before. (J., maths teacher)

Comments about student movement made implicit references to the space, since this much movement would not be possible in a traditional classroom, but the teachers did not discuss their facilitation of this aspect of the learning. Our observations during the week suggested that the 'Explanation' faculty had quite consciously tried to mirror the layout of the new school: they arranged and rearranged furniture within the hall during their day to facilitate a number of different groupings for different activities, moving from a whole group introduction, through four class-sized groupings to smaller groups scattered through the hall (see figures 1 and 3 ). The teachers in the other faculties tended to use a mixture of presenting to the whole group of students or small groups distributed in an ad hoc way around the hall. The 'Creation' faculty reported that they felt limited by the space available because it did not contain the ICT and other resources they would need to cover their curriculum area properly. They also commented in response to the slideshow of photographs from the week that bigger desks were necessary.

Insert Fig 3 here 
Since noise is frequently cited as a problem in open plan learning space, we specifically sought the teachers' views on this aspect of the experimental week through presenting a quotation from a student that 'noise goes high...'. Teachers from the 'Explanation' faculty felt that noise had been a problem and that students may have been distracted. Later in the discussion they also expressed concerns that distraction might be a particular problem in the open plan space of the new school for older students working towards public exams. However, it was also mentioned that the new building included 'sound booths', which they felt should help with problems of noise being distracting. In contrast, the 'Creation' teachers reported that noise had not been a problem on their day, commenting that they 'didn't notice the noise as much as when we're in the classroom', reflecting again the nature of the subject matter of their curriculum, as well as perhaps their discipline-specific cultural expectations. Thus for both faculties, the design of the new building was anticipated to solve problems relating to noise, even if, for 'Explanation', these problems were themselves created by the layout and intended usage.

Overall, despite limited discussion of the use of space during the experimental week, the teachers' conversations did reveal aspects of their attitudes towards the new building's design. For the 'Creation' teachers, this was generally part of their anticipation and looking forward, actively preparing for the new building. For example, in a discussion of timetabling problems it was suggested that these 'should get better in the new building'. The 'Explanation' teachers also mentioned the new building, but for them the important aspect seemed to be the ability of the design to ameliorate some of the problems of enquiry or collaborative teaching and learning. Senior leaders commented that they felt the experimental week had had an impact on preparations for the new school, but their perceptions were similarly not focused on the physical environment of the new building:

This week has accelerated that process of discussion and I think some teachers are excited by it, and some are hiding under their duvet. (School leader) 


\section{Concluding thoughts}

This article has presented the experiences and views of two faculty groups of secondary school teachers in relation to a school decision to change pedagogical practices. Their perspectives on teaching and learning, in their current setting, during the experimental week of enquiry learning and as anticipated in a new environment, have been considered in light of the school context and the intentions of the school leaders initiating this change. The elements of an educational learning environment that were previously identified as important - that is pedagogical intentions and practices, organisational aspects, and the nature of the space itself - have indeed structured the understandings being developed in this school. We were also interested in the culture of learning in the school, since culture is important in circumstances of change and, in this case, the senior leaders were aware of a need to effect cultural change within staff and students in order to support the pedagogical change they wanted to see enacted. To conclude, we will consider these issues by summarising what appeared to be happening in this school, how this relates to other reported experiences and previous research, and the implications of this for understanding change within wider societal contexts.

\section{Change in education}

As discussed above, research shows how difficult change in school practices is, yet Priestley and colleagues remind us that on occasion 'change does occur' (2011: 267). It has been argued, however, that educational establishments are inherently conservative due to their societal role in transmitting knowledge and culture from generation to generation (Young \& Muller, 2010:15). Certainly, in this school, many of the concerns about changing practices expressed by the teachers related to wider, societal requirements of the educational system in the UK, such as conveying core curriculum knowledge and preparing students for exams, success in which was understood by all staff to be a particular worry for this school. Another strand of the teachers' concerns, however, related to internal issues for the school, including organisational problems, such as planning time, and working effectively across the school to produce a coherent learning experience. This range of concerns, and the differing types and levels of action needed to address them, demonstrates the challenge of pursuing change in educational practices. 
The complexity of educational settings that this points to has been discussed by researchers investigating the implementation of a class size reduction policy in the US who note that even a clearly defined objective is not 'a single policy variable but a cog in the larger machine of schooling' (Graue et al. 2007: 696). In describing his conception of 'classroom climate', Moos is careful to draw attention to this complexity, by proposing that, despite the depiction of single directions of influence between factors, he conceives of causal affects happening in all directions. Also, it is interesting to note that some of Moos' examples of influence relate to the selection of students and teachers to particular settings or styles of organisation as well as to the possibility of the behaviour of teachers and students being affected by physical or organisational features. In the case of the school we researched, there is the suggestion of change in pedagogy and culture eventually being enacted through a mixture of these processes: some teachers intended to change their practices, but others were intending to leave, presumably to be replaced by teachers who preferred enquiry learning and collaborative use of educational space.

\section{Challenges}

As mentioned in the introduction to this paper, there is a body of research concerning the difficulties of implementing team teaching and the challenges of the related issue of teaching and learning in open plan educational space. However, it is important to note that there are also published studies of schools where change to cross-curricular, student-centred learning supported by flexible space and staffing has been successful (e.g. Gislason, 2010; Briggs, 2001: 184-6).

The responses from the teachers in our case study clearly show that many of them are already struggling with collaborative teaching, and all were concerned about managing joint planning. Some were additionally raising concerns around whole school coordination. Recent US research considering team teaching would suggest that the teachers' anxiety was appropriate. York- Barr and colleagues warn against supposing that moving to collaborative teaching is a 'relatively straight-forward...structural change' (York- Barr et al.,2007:331), while the class size reduction researchers comment that it is 'erroneous to throw two teachers together and expect them to work 
in tandem' (Graue et al., 2007: 696). Both teams of researchers recommend specific training and professional development together with time allocated for collaborative planning.

As discussed above, the use of space was not yet an issue for these teachers, with the experimental week treated as a 'novelty' in spatial terms, though arguably seen as more of a dry run in terms of pedagogy and interdisciplinary collaboration. One teacher we spoke to queried the plan for the organisational change (in timetabling and from departments to faculties) to precede the change in physical space. Although this plan seems sensible in terms of recognising that changes to physical settings do not by themselves change pedagogical practices, it does raise the question of whether the logic of the planned changes were being adequately explained to the teaching staff. In the case study school studied by Briggs, which appears to have similar values regarding learning to our research school, changes to the timetable were also made first, followed by physical change to accommodate the new pedagogy. However, change seems to have taken place over a longer period ( 5 to 6 years) than is intended in the school we studied, and to have happened more organically. Notably, the innovative approach to learning only takes place one day per week.

It might be suggested that the school leaders in our research school had failed to appreciate the scale of the change they were hoping to enact, although they understood the logic of the process of change and had a very clear appreciation of the wider context and the external challenges that the school was facing. Perhaps this understanding of the wider context put them under pressure to move fast and contributed to their missing or under-estimating the issues raised by the teachers as a result of the experimental week.

\section{Effecting cultural change in this school}

We began this paper by considering the potential for school communities in the current educational context to self-determine and enact change. We also recognised the importance of participatory approaches to change given the contribution of cultural understandings to the use of educational space and the pedagogical practices adopted. It is notable, however, that there is less clarity in 
how a school culture develops: how does it emerge from, but also define, the local 'ways of doing things' produced by the confluence of practices, organisation and space?

In this school, the coming changes to the physical setting were intended to support the desired pedagogical and cultural changes. New organisation, in the form of faculties and block timetabling, that coheres with the desired use of the space as to be put in place first, followed by the physical changes, with the combination intended to embed pedagogical change. Three key aspects of the school approach were therefore subject to direct change, with the school culture underlying and influencing these other elements. As Gislason has argued (2010; 2011), when cultural, organisational and spatial elements are mutually supportive, the school's educational approach will tend to endure and develop, rather than slipping into some uncomfortable accommodation of conflicting elements. The question for this school is whether they had begun to progress towards a coherent, balanced situation.

It is difficult to assess the cultural aspects, although it seems likely that they will indeed be central to the success of the proposed change. It was evident from discussions and interviews that the teachers did to some extent share the values relating to enquiry learning as envisaged by the school leaders. It seems, however, that this could show adherence to a general 'idealised practice', which values student autonomy over teacher-directed learning. In contrast, the sharing of particular cultural and pedagogical values within the school seemed less evident and perhaps required time to be articulated and developed. Furthermore, the concerns expressed by some of the teachers about school level coordination and organisation suggest that there are other problems with shared understandings across the school. The leaders wanted the teachers to engage with and practice the new approaches, while the teachers looked to the leadership team to make time and space available for the many different pieces of collaborative planning required. There are hints here of fragmentation within the culture of the school which seem likely to make the substantial pedagogical change the school was planning more difficult to enact successfully. 
The wider circumstances of the school are also important in understanding what was happening. Despite the school leaders being aware of the external pressures that had driven their decisions regarding change, they did not seem to have made their interpretation and reasoning clear to the rest of the staff. Furthermore, their comments show that they were not sympathetic to how these pressures were interpreted by some teachers as a reason to doubt the wisdom of change. In fact, in the two years following our research involvement, the school came under increasing pressure from the external forces of inspection and further reorganisation. The inspection reports are critical of communication and consistency in the school, particularly relating to student behaviour, which could be seen as corroborating the concerns voiced by some of the teachers we worked with. The reports, however, also reveal a tendency of the inspectors to see the open spaces of the new school premises as contributing to the problems, and it seems likely that there will be pressure to alter these and so draw back from the pedagogical and cultural change previously envisaged. It would appear that in the end this school is not to be allowed the 'earned autonomy' (Hargreaves, 2002: 206) that schools in more fortunate circumstances can expect.

\section{References}

Bragg, S. and Buckingham, D. (2008) 'Scrapbooks' as a resource in media research with young people. In P. Thomson (ed.) Doing Visual Research with Children and Young People. London: Routledge.

Bennett, N., Andreae, J., Hegarty, P., and Wade, B. (1980). Open plan schools. Windsor: Schools Council Publishing/NFER.

Briggs, A. (2001) Managing the Learning Environment In D. Middlewood and N.Burton (eds) Managing the Curriculum. London: Sage.

Clark, A. (2010) Transforming Children's Spaces: children's and adults' participation in designing learning environments. Abingdon: Routledge.

Clark, J. (2012) Using diamond ranking as visual cues to engage young people in the research process, Qualitative Research Journal, 12 (2): 222-237. 
Cooper, I. (1981). The Politics of Education and Architectural Design: the instructive example of British primary education. British Educational Research Journal 7(2): 125-136.

Cuban, L. (1993). How teachers taught: Constancy and change in American classrooms, 1890 1990 (2nd ed.). New York and London: Teachers College Press.

Gislason, N. (2010). Architectural design and the learning environment: A framework for school design research Learning Environments Research, 13, 127-145.

Gislason, N. (2011) Building innovation: History, cases, and perspectives on school design, Big Tancook Island, Nova Scotia: Backalong Books.

Graue, E., Hatch, K., Rao, K., and Oen, D. (2007) The wisdom of class-size reduction, American Educational Research Journal, 44: 670-700.

Hargreaves, A. (2002) Sustainability of educational change: the role of social geographies. Journal of Educational Change 3: 189-214.

Horne, S. C. (1999) Classroom environment and its effects on the practice of teachers. PhD thesis, University of London.

Horne-Martin, S. (2002). The classroom environment and its effects on the practice of teachers. Journal of Environmental Psychology 22(1-2): 139-156.

Lowe, R. (2007) The death of progressive education :how teachers lost control of the classroom London : Routledge

Moos, R H (1979) Evaluating Educational Environments, San Francisco: Jossey-Bass

Ouston, J., Maughan, B. and Rutter, M. (1991) Can Schools Change? II: Practice in Six LondonSecondary Schools. School Effectiveness and School Improvement 2(1): 3-13

Priestley, M., Millera, K., Barrett, L. and Wallace, C. ( 2011)Teacher learning communities and educational change in Scotland: the Highland experience British Educational Research Journal 37(2): 265-284

Sigurðardóttir, A.K. \& Hjartarson, T. (2011). School buildings for the 21st century. Some features of new school buildings in Iceland. CEPS Journal 1(2): 25-43.

Thomson, P. (2007) Whole school change: a review of the literature. London: Arts Council England Thomson, P., McGregor, J., Sanders, E and Alexiadou, N. (2009) Changing schools: more than a lick of paint and a well-orchestrated performance? Improving Schools 12(1): 43-57 
Uline, C. L., Tschannen-Moran, M., \& De Vere Wolsey, T. (2009). The walls still speak: The stories occupants tell. Journal of Educational Administration, 47(3), 400-426.

Woolner, P. (2010). The design of learning spaces. London: Continuum.

Woolner, P, Hall, E, Wall, K and Dennison, D. (2007) Getting together to improve the school environment: user consultation, participatory design and student voice. Improving Schools, 10(3), 233-248).

Woolner, P., Hall, E., Clark, J., Tiplady, L., Thomas, U., \& Wall, K. (2010). Pictures are necessary but not sufficient: Using a range of visual methods to engage users about school design. Learning Environments Research, 13(1), 1-22.

Woolner, P., Clark, J., Laing, K., Thomas, U. \& Tiplady, L. (2012a). Changing Spaces: Preparing Students and Teachers for a New Learning Environment. Children, Youth and Environments 22(1): $52-74$.

Woolner P, McCarter S, Wall K, Higgins S. (2012b) Changed learning through changed space: When can a participatory approach to the learning environment challenge preconceptions and alter practice? Improving Schools 15(1), 45-60.

York-Barr, J., Ghere, G., and Sommerness, J. (2007) 'Collaborative teaching to increase ELL student learning: A three-year urban elementary case study', Journal of Education for Students Placed at Risk, 12: 301-335.

Young, M \& Muller, J. (2010) Three Educational Scenarios for the Future: lessons from the sociology of knowledge European Journal of Education 45(1) 11-27 

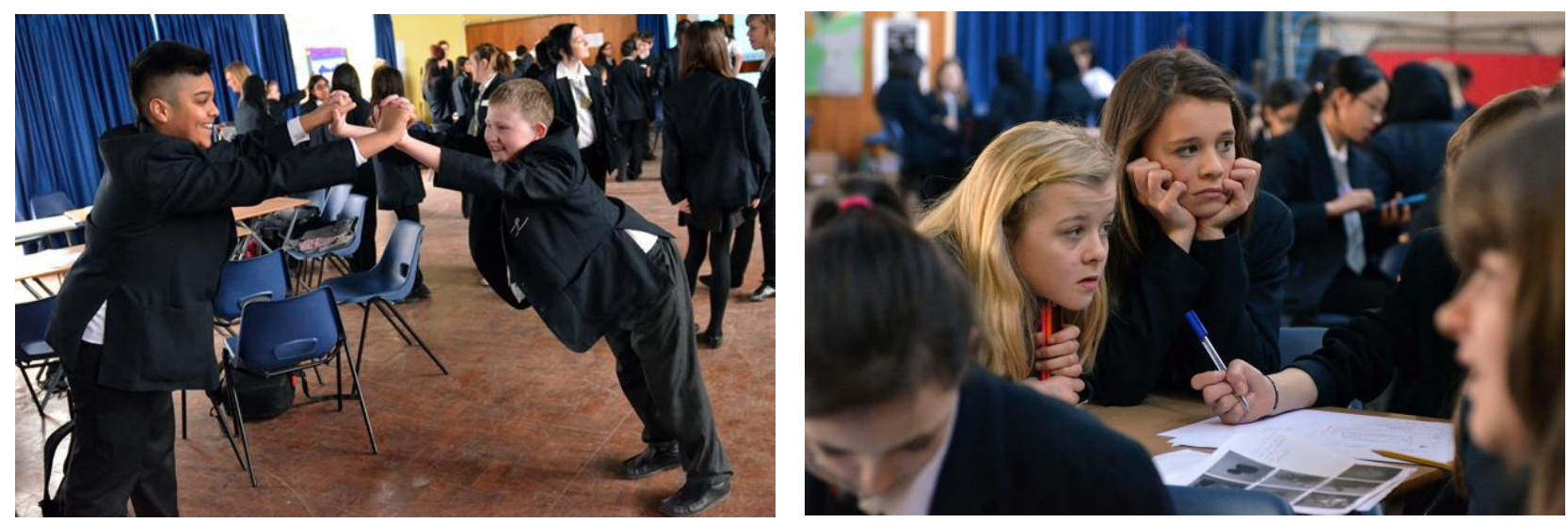

Figure 1: Students engaged on enquiry learning days organised by 'Explantion' (left) and

‘Creation' (right) Photos: Keith Pattison

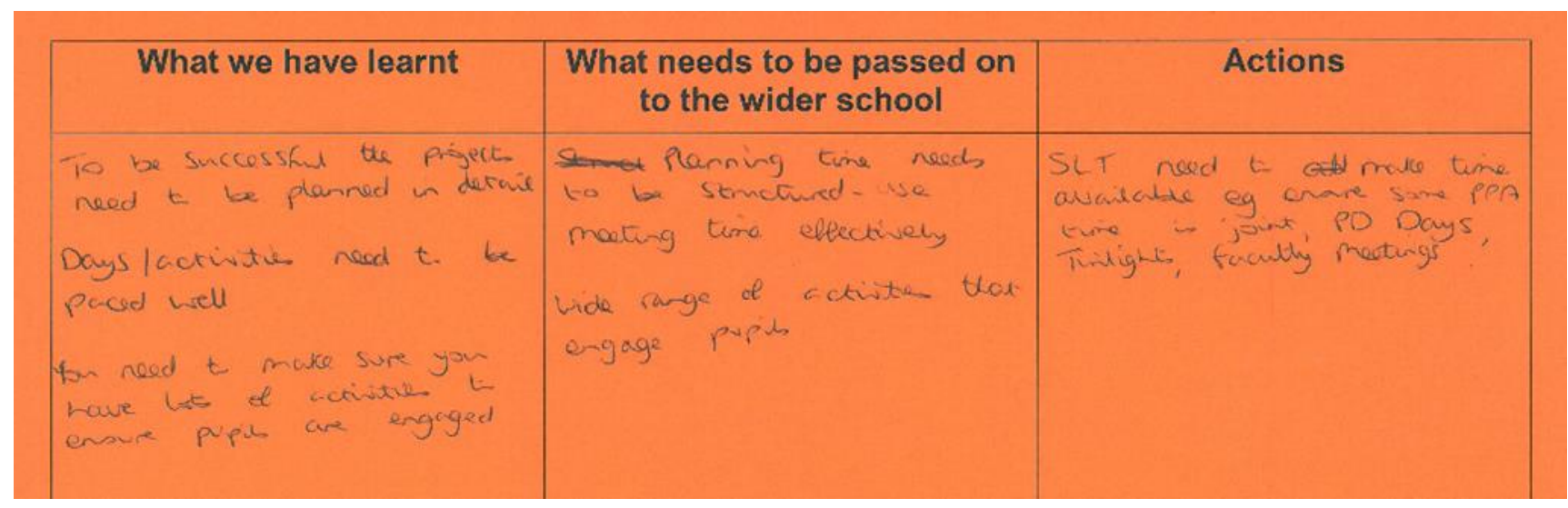

Figure 2: Response sheet for teachers' Day 2 from 'Creation' faculty
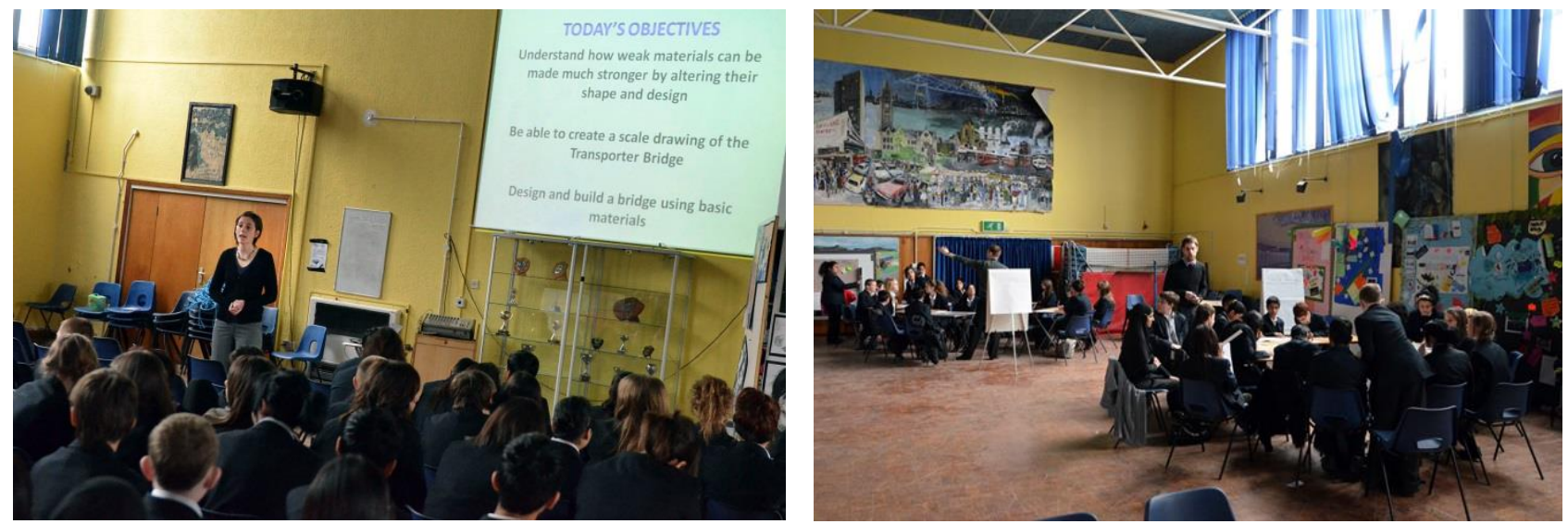

Figure 3: 'Explanation' teachers explicitly attempted to organise space to mirror new building: lecture space (left), class-sized grouping (right) and smaller groups (see Figure 1) Photos: Keith Pattison 